\title{
O DIREITO CANÔNICO ENQUANTO CIÊNCIA JURÍDICA: UMA REVISÃO DE LITERATURA
}

\author{
CANON LAW AS A LEGAL SCIENCE: A LITERATURE REVIEW
}

\author{
Pablo Henrick Oliveira Leite ${ }^{1}$
}

RESUMO: O direito canônico é o ramo do direito que ordena a Igreja Católica enquanto instituição humana, trata-se de um valioso instrumento que visa não só a organização interna eclesiástica, mas tem sua importância sob o direito ocidental enquanto ciência jurídica. O presente estudo realizou através de uma revisão bibliográfica na literatura especializada uma análise sobre o direito canônico e sua importância enquanto ciência do direito. A partir da análise bibliográfica foram selecionados 19 documentos leigos e eclesiásticos que melhor representassem o tema. Diante do presente trabalho é possível destacar a importância do direito canônico e sua influência enquanto ciência jurídica pois a partir do conhecimento do direito canônico é possível compreender as bases do direito no ocidente, buscando evidenciar suas fontes, princípios e a aplicações atuais. Ressalta-se a deficiência bibliográfica acerca do tema, restringindo-o muitas vezes apenas ao âmbito eclesial.

Palavras-chave: Direito Canônico. Ciência Jurídica. Igreja Católica.

ABSTRACT: Canon law is the branch of law that orders the Catholic Church as a human institution, it is a valuable instrument that aims not only at the internal ecclesiastical organization, but has its importance under Western law as a legal science. The present study carried out, through a bibliographic review in the specialized literature, an analysis of canon law and its importance as a science of law. From the bibliographic analysis, ig lay and ecclesiastical documents were selected that best represented the theme. In view of the present work, it is possible to highlight the importance of canon law and its influence as a legal science because from the knowledge of canon law it is possible to understand the bases of law in the West, seeking to highlight its sources, principles and current applications. The bibliographic deficiency on the subject is highlighted, often restricting it only to the ecclesial scope.

Keywords: Canon Law. Legal Science. Catholic Church.

\footnotetext{
Graduando no décimo período em Direito pelo Centro Universitário Assunção . Email:pablohenrickleite@gmail.com
} 


\section{INTRODUÇÃO}

Toda organização social requer um ordenamento no qual sejam compreendidos um conjunto de normas e regras que conduza e limite os direitos de deveres daqueles que compõem e dão corpo a tais grupos. (DIEL, 2021)

Robert Alexy (2009) entende que a propagação de variados conceitos e sobre a definição de direito é causada pela atribuição de três elementos fundamentais, a legalidade, da eficácia social e da correção material. Entretanto existe também a chamada A Ciência Jurídica, que objetiva estudar o direito e fenômeno jurídico "como ele se concretiza no espaço e no tempo"

O Direito canônico pode ser descrito inicialmente como o ramo do direito que rege a Igreja Católica² (GIUDICE, I946). e a sua história e concepção está ligada diretamente com a história do direito no ocidente,

Em 1955 o canonista José Antônio Martins Gigante, já definia o Direito Canônico como ramo dogmático do Direito que frisa o aspecto eminentemente jurídico: "Direito Canônico é o sistema ou complexo de leis com que a Igreja regula a sua atividade social específica e a de seus membros como tais"

Diante da perspectiva apresentada $O$ presente trabalho tem como objetivo elucidar os principais aspectos relacionados ao direito canônico enquanto uma ciência jurídica ao longo dos séculos e Trata-se de uma revisão narrativa de literatura, na qual apresenta-se como uma vantagem a inclusão de múltiplos estudos com diferentes delineamentos de pesquisa para melhor compreensão do tema estudado.

\section{A HISTÓRIA DO DIREITO CANÔNICO}

O Papa Francisco na introdução de sua Constituição Apostólica Pascite Gregem $D e i^{3}$, reafirmava de forma clara e objetiva, mas não menos profunda, a essência do ordenamento jurídico da Igreja Católica Apostólica Romana, no qual se dá o nome de Direito Canônico:

Avançando na sua peregrinação terrena, desde os tempos apostólicos, a Igreja tem vindo a dar-se leis para o seu modo de agir que ao longo dos séculos veio a

\footnotetext{
${ }^{2}$ DE L GIUDICE, Vincenzo. Sommario di diritto canônico. Milano: Giuffrè, 1946. p.23

${ }^{3}$ Constituição Apostólica Pascite Gregem Dei com a qual é reformado o Livro VI do Código de Direito Canônico (23 de maio de 2021), por Vossa Santidade Papa Francisco.
} 
compor um corpo coerente de normas sociais vinculativas, que conferem unidade ao Povo de Deus e cuja observância os Bispos são responsáveis"' (FRANCISCO, 2021).

A Igreja durante os séculos foi formando a sua identidade jurídica por meio de um ordenamento próprio, que foi inspirado de acordo com o pensamento vigente de cada período histórico-social, associando questões tanto relacionadas à fé, como a organização de suas estruturas terrenas. (LOMBARDIA, 2008).

Segundo Steffen (2015), o Direito Canônico está totalmente intrínseco na Igreja enquanto povo de Deus ${ }^{4}$, não correspondendo apenas à hierarquia da Igreja, mas uma realidade que compreende também todos os fiéis que professam a mesma fé e crença, no qual ela a partir das suas normas e condutas tipificadas no código, expressa as garantias, direitos e deveres fiéis leigos e leigas, não manifestando apenas apontamentos de obediência.

Para que se chegasse a esse "sistema jurídico eclesiástico" (BACELAR, 2018), foi preciso um longo caminhar que remonta essencialmente a partir do Direito Divino, provindo da Revelação de Deus aos homens, no qual o direito canônico é uma expressão, que não contrapõe-se aos principais elementos do direito humano, mas complementam-se, conforme o próprio Pontífice João Paulo II escreveu em sua Constituição apostólica Sacrae Disciplinae Leges 5 , com a qual promulgou o atual código de direito canônico em 1983:

O Código, como principal documento legislativo da Igreja, baseado na herança jurídica e legislativa da Revelação e da Tradição, deve considerar-se o instrumento indispensável para assegurar a ordem tanto na vida individual e social, como na própria atividade da Igreja. Por isso, além de conter os elementos fundamentais da estrutura hierárquica e orgânica da Igreja, estabelecidos pelo seu Divino Fundador ou baseados na tradição apostólica ou na mais antiga tradição, e ainda as principais normas referentes ao exercício do tríplice múnus confiado à própria Igreja, deve o Código definir também as regras e as normas de comportamento. (JOÃO PAULO II, I983, p.ro)

O desenvolvimento do direito canônico inicia-se no século IV, nos assegura Brandão (2017) , mas é possível observar que antes disso os primeiros cristãos “ regeram a vida coletiva das comunidades aplicando os textos do Novo Testamento, a tradição

\footnotetext{
${ }^{4}$ Segundo Steffen: 'Depois da II Guerra Mundial, o desenvolvimento da teologia deu relevo à designação da Igreja como povo de Deus. Conceito usado não exclusivamente, mas como complemento das demais designações" (pag.20).

${ }^{5}$ Constituição Apostólica Sacrae Disciplinae Leges, datada de 25 de janeiro de 1983, que promulgou o atua código de direito canônico.
} 
apostólica, os costumes e as decisões adotadas pelos bispos em sua qualidade de sucessores dos apóstolos[...]” (LOMBARDIA, 2008), e assim iam criando no seio da sociedade uma nova configuração jurídica.

Para Boeira (2017), a base do direito canônico está totalmente entrelaçada com a própria teologia, com os fundamentos da fé cristã, com a defesa da fé, com situações típicas do cotidiano dos primeiros cristãos e neste ponto destaca-se as grandes figuras dos Padres da Igreja, pois foram eles que se dedicaram a difundir a fé a cristã nos campos da teologia e filosofia, combatendo principalmente as heresias. E reafirmando os dogmas da fé, mas influenciando também no campo do direito.

Os textos das tradições canônicas foram formando-se de forma particularizada, fruto do magistério da Igreja, chegando ao seu ápice com o advento da idade média, conforme elucida Brandão (2020, p.22): “[...] é de singular importância para a formação do direito a atuação dos bispos de Roma, mais tardes chamadas de Papas, na institucionalização da Igreja e os Concílios, que nesse tempo era reunião dos bispos da Igreja Católica[...]”

O período chamado Direito canônico clássico ${ }^{6}$ que corresponde aos anos de 1140 e 1335, é a solidificação do direito canônico como uma das principais fontes de direito na Europa, principalmente pela obra escrita pelo monge Graciano ${ }^{7}$, que foi o grande responsável por copilar os escritos eclesiais que se referiam ao direito da Igreja e logo tomou uma grande repercussão nas Universidades à época, como elucida Brandão:

$\mathrm{Na}$ formação do direito canônico, o Decreto de Graciano, chamado pelo autor de Concordia discordantium canonum, é um verdadeiro "divisor de águas". A obra foi composta por volta de II40 e marca a divisão do nosso objeto de estudo em duas fases, a saber: a fase precedente ao Decreto, chamada pelos estudiosos de fase do direito sem juristas e a fase que se inicia com a obra de Graciano, que é a fase da ciência do direito canônico (BRANDÃO, 2017)

Durante a idade média, foram diversas as tentativas de copilar o direito canônico em obras posteriores á obra de Graciano, fazendo com que essas diversas obras como os decretais e as normas pontifícias fossem reunidas em um único corpo jurídico, no qual deu-se o nome de Corpus Iuri Canonic, formado por algumas obras clássicas, conforme cita

\footnotetext{
${ }^{6}$ Definição utilizada por Lombardia. Sobre o assunto ver: LOMBARDÍA, Pedro. Lições de direito canônico: Introdução direito constitucional parte geral. São Paulo: Loyola, 2008. P.32

${ }^{7}$ Conferir em: Brandão, Cláudio. Lições de história do direito canônico e história do direito em perspectiva. Belo Horizonte, D'Plácido, 2017. p.20.
} 
Lombardia (2008, p.38) : “[...] O decreto de Graciano, as Decretais de Gregório IX, o livro de Bonifácio VIII e as Decretais clementinas [...]

Com a Modernidade, o direito canônico sofreu diversas modificações, devido aos fatos históricos-sociais que aconteciam na Europa, sobretudo com a reforma protestante.

Apesar da resposta de reorganização da Igreja com a contrarreforma, principalmente a partir do Concílio de Trento ${ }^{8}$, as normas jurídicas da Igreja também sofreram consequências, uma vez que elas não correspondiam plenamente a esta nova fase eclesial, conforme exemplifica Lombardia (2008, p.42): “[...] Não obstante o corpus em plena idade moderna, não podia ser aplicado com os mesmos critérios com que foram forjados $[\ldots]$

As disposições papais chamadas de bulários foram aos poucos matizando o conteúdo do corpus, porém foi em 1588 que houve uma grande mudança na realidade jurídico eclesiástico da Igreja, com a criação da cúria Romana pelo Papa Sisto V.

Continua Lombardia (2008, p 42.): “[...] a constituição Immensa aeterni ${ }^{9}$ um complexo burocrático denominada cúria Romana cujos organismos, com competências administrativas ou judiciais resolveram uma infinidade de questões retificando ou ampliando o conteúdo do corpus [...]”

Apesar das inúmeras mudanças que ocorreram nos séculos seguintes, tanto para a Igreja quanto para a sociedade como um todo, o corpus iuris canonic ainda continuava em vigor, sem que nenhum outro viesse a substituí-lo, somente no século XIX, com o advento do Concílio do Vaticano I (I869-1870) é que as ideias de consolidação de um novo código começaram a tomar força (STEFFEN, 2014).

\footnotetext{
${ }^{8}$ O concílio de Trento, segundo Lombardia: "O concílio de Trento ( 1545 -1563), que além de reafirmar os princípio dos dogmas católicos que haviam sido postos em dúvidas pelos protestantes, dá impulso- tardia porém eficazmente - a uma reforma disciplinar da Igreja que vinha sendo pedido pelos cristãos mais lúcidos desde a crise do direito clássico." (LOMBARDIA, p.4I)

9 João Paulo II , em sua encíclica Pastor Bônus de 1988, acerca da Cúria Romana, explica o que foi a Constituição Immensa Aeterni Dei: " a Cúria Romana surgiu para um único fim: tornar cada vez mais eficaz o exercício do múnus universal de Pastor da Igreja, que o próprio Cristo confiou a Pedro e aos seus Sucessores, e que pouco a pouco foi crescendo, adquirindo dimensões cada vez mais amplas. Efectivamente, o meu Predecessor Sisto V assim reconhecia na Constituição Apostólica Immensa aeterni Dei: "O Romano Pontífice, que o Cristo Senhor constituiu cabeça visível do seu Corpo, a Igreja, e quis que levasse o peso da solicitude de todas as Igrejas, chama para junto de si e assume muitos colaboradores numa tão imensa responsabilidade..., a fim de que, compartilhando com eles (os Cardeais) e com as outras Autoridades da Cúria Romana o encargo ingente das preocupações e incumbências, Ele, que governa o timão de um poder tão grande, com o auxílio da graça divina, não venha a sucumbir"
} 
No entanto, durante o Concílio do Vaticano I, não houve mudanças no corpo jurídico da Igreja, estas foram efetivadas somente em 1917 com a promulgação do primeiro Código de Direito Canônico, pelo Papa Bento XV em 27 de maio de 1917 conforme elucida Steffen, (2014, 6I): “[...] O primeiro Código canônico facilitou o desenvolvimento ordenado da vida da Igreja e o progresso da ciência do direito canônico, porém, não foi objeto de atualização em matéria de doutrina e jurisprudência. [...]”

O Código de 1917, ficou em vigor por praticamente 6 décadas desde sua promulgação, até ser substituído pelo atual código promulgado pelo Papa São João Paulo II em 25 de janeiro de 1983, fruto das inúmeras mudanças ocorridos anos atrás pelo Concílio do Vaticano II (1962-1965).

Nos elucida Steffen:

A renovação da Igreja impulsionada pelo Concílio Vaticano II exigia uma profunda reforma da legislação eclesiástica. O processo de revisão da legislação culminou com a promulgação do novo Código de direito canônico, pelo Papa João Paulo II, em 1983. O Código em vigor tem 1.752 cânones organizados em sete livros: normas gerais, povo de Deus, múnus de ensinar, múnus de santificar, bens temporais, sanções e processos. Não é a única lei da Igreja latina. Seu próprio texto remete a leis especiais para a regulação de determinadas matérias, como a estrutura e o funcionamento da Cúria romana (cf. cânon 360) ou o procedimento a seguir nas causas de beatificação. (STEFFEN, 2014)

\section{A NATUREZA DO DIREITO CANÔNICO: O DIREITO CANÔNICO ENQUANTO CIÊNCIA JURÍDICA}

Conforme foi exposto, a história do Direito Canônico culmina no Concílio do Vaticano II, com a promulgação do Código de 1983, pois aquilo que os padres conciliares conceberam e ao mesmo tempo reafirmaram em relação a doutrina e a lei, estão postos em prática neste código.

Para Sampel (2018) ${ }^{\mathrm{IO}}$, o código canônico é fruto do Concílio do Vaticano II, pois retrata de maneira fiel em seu ordenamento o pensamento do concílio, as suas disposições e os seus princípios, sendo uma expressão jurídica do Concílio, o que levou ao Papa São João Paulo II a considerá-lo como o último documento pós-conciliar.

O Concílio do Vaticano II personificou o direito canônico a sua luz, reafirmando o seu aspecto jurídico, mas o colocando em consonância com a realidade eclesial da Igreja

\footnotetext{
${ }^{\text {Io }}$ Lombardia, 2008, p.32
} 
contemporânea, , reafirmando a sua realidade pastoral, conforme exemplificou o Papa Francisco (2017): “[...]a exigência de que o direito canónico seja sempre conforme com a eclesiologia conciliar e se faça instrumento dócil e eficaz de tradução dos ensinamentos do Concílio Vaticano II na vida diária do povo de Deus.”.

Após o Concilio do Vaticano II, houve as tentativas de situação do ordenamento jurídico da Igreja dentro do magistério, tais tentativas, conforme exemplificou o canonista Lombardia (2014), buscaram reservar o direito na Igreja a uma visão estritamente teológica.

Foi o teólogo alemão Klaus Morsdorf (1909-1989), pertencente a Escola de Munique, o principal expoente, que segundo PINHO (2020) “[ [...]considerava o direito canônico como uma disciplina teológica com método jurídico. [...]” porém , continua o autor: “[...] Tal interpretação é limitada, pois o direito canônico possui uma linguagem e um método próprio, diferentemente da metodologia e da linguagem teológicas.[...].

Para Pinho (2020): “[...] por mais que o direito canônico tenha interferências diretas na vida pastoral da Igreja e estabeleça diálogo com a Teologia, ela é uma ciência com uma epistemologia específica.".

No entanto, a grande maioria dos doutrinadores refutam essa ideia e afirmam que o

Direito Canônico é essencialmente ciência do Direito, mesmo que ele seja inspirado em leis divinas, conforme nos é elucidado:

Se perguntarmos o que é Direito Canônico, podemos também completar nossa interrogação fazendo uma outra pergunta suplementar: o que não é Direito Canônico? Em primeiro lugar, o Direito Canônico não é Teologia prática, isto é, um estudo sistemático sobre as práticas eclesiais [...] o Direito Canônico não é um discurso da fé ou Teologia, nem tem preocupação de celebrá-la, como é próprio. (KLAUSNER apud GONÇALVES, 2019)

Uma vez superado isto, no entanto, na história do Direito, também encontramos doutrinadores que negaram o caráter jurídico do Direito Canônico, principalmente sob o argumento de que apenas o Estado era a principal fonte do Direito, diz Lombardia (2008): “com base em tal posição era inevitável afirmar que certas normas que não procedem da vontade do Estado, mas da igreja não podiam ser consideradas jurídicas" "II Tal argumento foi principalmente defendido pelo doutrinador italiano Francesco Carnelutti ${ }^{12}$ (1879-1965).

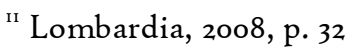

${ }^{12}$ Francesco Carnelutti (I879-1965), foi um renomado jurista italiano, segundo Lombardia: '[...] que pôs em dúvida o caráter jurídico do ordenamento canônico, por entender que suas normas contemplavam a relações
} 
Para aqueles doutrinadores nos quais somente o Estado era fonte de Direito, podendo ser adotado apenas aquelas regras cujo direito estatal não era contraposto, mas complementar ou aqueles normas nas quais o direito canônico era vinculado ao direito estatal.

Outro questionamento que levou a dúvidas enquanto a juridicidade do direito canônico, foram a respeito do seu caráter não vinculativo, conforme elucida Lombardia (2008): “[...]fundamentada nas doutrinas que consideravam o direito obrigatório sem possibilidade de oposição já que só o estado disponha da força decoração necessária para fazer cumprir as normas inclusive quando os destinatários não o fizessem de maneira voluntária.”.

No entanto, essas questões doutrinárias que afirmavam contra a antijuridicidade do Direito Canônico, conforme elucidam Klausner e Rosa (2019): "O sistema normativo oriundo da Igreja Católica, como o sistema normativo que organiza todo o tipo de corporação ou pessoa jurídica, portanto, é reconhecido pelo próprio Estado como Direito.”

Segundo estes autores, o sistema de normas da Igreja é essencial porque atinge a própria existência da Igreja como pessoa jurídica e sua personalidade, visando que esta seja reconhecida pelo núcleo social e pelo Estado.

Neste ponto, podemos usar as esclarecedoras palavras do então Papa Bento XVI, a respeito do caráter jurídico, teológico e pastoral do Código de Direito Canônico, no seio da Igreja, por ocasião da promulgação da Carta Apostólica sob forma de "Motu proprio" : Ominiun In Mentem ${ }^{13}$

A Constituição Apostólica Sacrae disciplinae leges, promulgada a 25 de Janeiro de 1983, voltou a chamar a atenção de todos para o facto de que a Igreja, enquanto comunidade espiritual e visível e ao mesmo tempo ordenada hierarquicamente, tem necessidade de normas jurídicas "a fim de que o exercício das funções que lhe foram confiadas por Deus, especialmente a do sagrado poder e da administração dos sacramentos, possa ser adequadamente organizado". Em tais normas, é necessário que resplandeça sempre, por um lado, a unidade da doutrina teológica e da legislação canónica e, por outro, a utilidade pastoral das prescrições,

do homem com Deus e não estavam voltadas para os ajuste de interesse entre homens." (LOMBARDIA, 2008, P.32).

${ }^{13}$ Omnium in mentem trata-se de um motu próprio de 26 de outubro de 2009, publicado em is de dezembro do mesmo ano, pelo qual o Papa Bento XVI modificou cinco cânones do Código de Direito Canônico de 1983, dois relativos ao sacramento das ordens sagradas, o outro três sendo relacionados ao sacramento do casamento. 
mediante as quais as disposições eclesiásticas estão ordenadas para o bem das almas.

Com isso, o papa reafirma que o direito canônico é um fundamento jurídico dentro da Igreja, no entanto, sem perder o seu aspecto teológico uma vez que está enraizado na doutrina teológica e ao mesmo reforçando claramente o seu aspecto pastoral.

\section{AS FONTES DO DIREITO CANÔNICO: DIREITO HUMANO E DIVINO}

O Papa São João Paulo II, no qual promulgou o novo Código de Direito Canônico em 25 de janeiro de 1983, afirmava que a sua principal fonte era o Direito Divino, esclarecendo assim reducionismos, que asseguravam que o Direito Canônico era um mero elemento jurídico consequência de um positivismo jurídico no seio da Igreja. (JOÃO PAULO II, 1983)

O Direito Divino é a primeira fonte do Direito Canônico, segundo a doutrina, o direito divino podem ter duas origens diferentes, porém não contraditórias, conforme nos explica Steffen (2014): "O direito divino abrange o natural e o positivo. O direito divino natural é o direito fundado na natureza social da pessoa humana. $O$ direito divino positivo é o direito que provém da Revelação divina."

Como Direito Divino natural, podemos verificar as condições antropológicas do homem: "Criado à imagem e semelhança de Deus" (Gênesis 1,26), a pessoa humana tem uma dignidade única, tal dignidade provém justamente da união profunda que existe entre a pessoa humana e seu criador, conforme exorta o Papa João Paulo II, em sua carta encíclica Evangelium Vitae ${ }^{I 4}$ : " todo o homem sinceramente aberto à verdade e ao bem pode, pela luz da razão e com o secreto influxo da graça, chegar a reconhecer, na lei natural inscrita no coração ( $(\mathrm{ff} . \mathrm{Rm}$ 2, I4-I5), o valor sagrado da vida humana desde o seu início até ao seu termo".

No entanto, esse Direito divino natural não é a única base no qual está enraizado o direito canônico na Igreja, porém não se contrapõe ao direito natural positivo, que é fruto da Revelação em Jesus Cristo, conforme nos diz Lombardia:

\footnotetext{
${ }^{14}$ A Encíclica Evangelium Vitae, publicada pelo Papa João Paulo II em 25 de março de i995, e que versa sobre o valor e a inviolabilidade da vida humana, reflete este tema em vários aspectos, dentre eles, um em especial a saber: a defesa da dignidade do embrião humano, que desde os primeiros instantes de sua existência deve ser acolhido e protegido em sua integridade.
} 
A rigor o direito natural nada pode nos dizer que afete especificamente o direito da igreja , uma vez que esta não responde a ordem natural, pois é a institucionalização da Redenção consumada por Cristo que eleva o homem a ordem Sobrenatural entretanto em virtude do princípio teológico segundo o qual a graça não destrói a natureza mas a aperfeiçoa ,um direito natural está em vigor na igreja enquanto da Razão de certos direitos e deveres naturais que o direito canônico não pode desconhecer[...] em resumo pode-se afirmar que o direito natural constitui o fundamento daquelas facetas que o direito canônico tem em comum com Os ordenamentos jurídicos Profanos (LOMBARDIA, 2008)

O Direito divino positivo nasce então a partir da Revelação divina nos dada pelo próprio Cristo, certos de que conforme afirma a Constituição Dogmática Dei Verbum ${ }^{15}$ "Aprouve a Deus. na sua bondade e sabedoria, revelar-se a Si mesmo e dar a conhecer o mistério da sua vontade (cfr. Ef. I,9)", isto é, Deus manifesta-se ao homem por meio de Jesus Cristo e pela revelação divina quis manifestar também os seus decretos.

Dado isso, o direito canônico tem por fonte principal a Revelação de Cristo, e seus ensinamentos que foram transmitidos através dos apóstolos e conversada no rico magistério da Igreja, desde os primeiros séculos até os dias atuais, formando então um conjunto específico de fundamentos nos quais o Direito Canônico se enraíza.

Steffen (2014), elucida que: “Com relação ao direito humano, em geral, se considera quase exclusivamente a intervenção da hierarquia eclesiástica, que contribui para determinar o direito canônico, mediante leis eclesiásticas e outras normas positivas." Ou seja, apesar do Direito Divino ser a principal fonte do direito canônico, este como fruto da realidade terrena da Igreja, também tem suas fontes aplicadas sobre o Direito humano.

Porém, nos afirma a doutrina que esses a origem divina e humana do Direito Canônico não se contrapõem, mas se complementam, uma vez que a própria Igreja, conforme reafirma a Constituição Dogmática Dei Verbum: "a Igreja ornada com os dons celestes não se devem considerar como duas entidades, mas como uma única realidade complexa, formada pelo duplo elemento humano e divino".

Cabe, portanto, a Igreja a real interpretação do Magistério e sua aplicação jurídica, conforme proferiu em discurso o Papa Francisco, no que diz respeito a interpretação da Palavra de Deus e a tudo aquilo que se diz respeito a ela: “[...] O Concílio lembrou com grande clareza: tudo o que está relacionado com a maneira de interpretar as Escrituras está, em última análise, sujeito ao julgamento da Igreja [...].”

\footnotetext{
${ }^{15}$ Constituição Dogmática Dei Verbum trata sobre as verdades da fé, é um documento conciliar, promulgado em 18 de novembro de 1965 pelo Papa Paulo VI.
} 
O direito canônico então passa a ter dois elementos fundamentais: $O$ elemento divino, do qual provém a sua fonte principal, o direito divino positivo e natural, e o direito humano, fruto da interpretação devidamente dada pelo magistério e pelo esforço da hierarquia da Igreja em aplicar a juridicidade.

Como conclusão, pode-se afirmar que o direito canônico é um único ordenamento jurídico, que tendo seu fundamento no direito divino, é fruto da conjunção harmônica de um elemento divino e um elemento humano.

\section{CONCLUSÃO}

A história do direito canônico está intrínseca na história do direito ocidental, uma vez que a Igreja Católica enquanto instituição enraizada no tempo e na história, organizou-se ao longo dos séculos nos tecidos sociais e como fruto dessa organização codificou-se direito canônico.

Ao percebemos o papel da Igreja Católica ao longo dos séculos na sociedade, podemos perceber seus frutos, sobretudo no que diz respeito as questões de cunho moral que formaram o direito no ocidente.

O Direito Canônico enquanto ciência jurídica resume-se não apenas como algo teológico ou religioso, mas é direito de fato, com características comuns e particularidades como as tantas outras ciências jurídicas, mas tendo como função principal buscar responder as necessidades da Igreja no mundo inteiro, que busca o equilíbrio entre a misericórdia e a justiça.

Estudos sobre este tema se fazem cada vez mais necessários pelos operadores do direito, uma vez que existe uma escassez ao referido tema, quando comparado com outros ramos das ciências jurídicas que são amplamente difundidas. Ao mesmo tempo, é necessário compreender a particularidade do Direito Canônico, que preza como princípio constitutivo a caridade.

\section{REFERÊNCIAS}

BACELAR, Renan Victor Boy. Direito canônico: vivências históricas e teóricas da cultura jurídica ocidental. Dissertação de mestrado. Universidade de Minas Gerais, 2018. 
BENTO XVI. Motu proprio ominiun in mentem. Vaticano: 2009. Disponível em: $\langle$ www.vatican.va $\rangle$. acesso em 28 de janeiro de 202I.

BOEIRA, Marcus. Lei e direito no período dos primeiros padres da Igreja: concepções jurídicas na patrística. Enciclopédia jurídica da PUC-SP. Celso Fernandes Campilongo, Alvaro de Azevedo Gonzaga e André Luiz Freire (coords.). Tomo: Teoria Geral e Filosofia do Direito. Celso Fernandes Campilongo, Alvaro de Azevedo Gonzaga, André Luiz Freire (coord. de tomo). I. ed. São Paulo: Pontifícia Universidade Católica de São Paulo, 2017. Disponível em: 〈https://enciclopediajuridica.pucsp.br/verbete/158/edicaoI/lei-e-direito-no-periodo-dos-primeiros-padres-da-igreja:-concepcoes-juridicas-napatristica> acesso em: 28 de janeiro de 2021.

BRANDÃO, Cláudio. Lições de história do direito canônico e história do direito em perspectiva. Belo Horizonte: Editora D'Plácido, 2017.

DE L GIUDICE, Vincenzo. Sommario di diritto canônico. Milano: Giuffrè, 1946.

FRANCISCO. Constituição apostólica pascite gregem dei. Vaticano: 2009. Disponível em: $\langle w w w . v a t i c a n . v a\rangle$. Acesso em: 2I de janeiro de 202I.

JOÃO PAULO II. Constituição apostólica: sacrae disciplinae leges. Vaticano: 1983. Disponível em: <www.vatican.va $>$. Acesso em: 25 de janeiro de 202I.

JOÃO PAULO II. Encíclica evangellium vitae. Vaticano: 1995. Disponível em: <www.vatican.va $\rangle$. Acesso em: 25 de janeiro de 202I.

JOÃO PAULO II. Constituição Apostólica: Pastor Bonus. Vaticano: 1988. Disponível em: <www.vatican.va $>$. Acesso em: 25 de janeiro de 2021.

KLAUSNER, Eduardo Antônio; DE CARVALHO ROSA, Pedro Paulo. Sobre a natureza do direito canônico. Lex Humana, v. Io, n. I, p. 40-62, 2018.

LOMBARDIA, Pedro. Lições de direito canônico. Edições Loyola, 2008.

PAULO VI. Constituição Dogmática Dei verbum. Vaticano: 1965 Disponível em: 〈www.vatican.va $\rangle$. Acesso em: 2I de janeiro de 202I.

PINHO, ADRIANO MENDES. As implicações do estudo da ciência canônica na pastoral. Scientia canônica. Santa Catarina, v. 3 n. 6: jul./dez. 2020.

SAMPEL, Edson Luiz. The diplomatic pact signed between Brazil and the Holy See, Revista de cultura teológica, v. 26, n. 91, p. 59-80, 2018.

STEFFEN, Carlos José Monteiro. Igreja e direito canônico: a dimensão jurídica do mistério da Igreja. 2014. Dissertação de Mestrado. Pontifícia Universidade Católica do Rio Grande do Sul. 